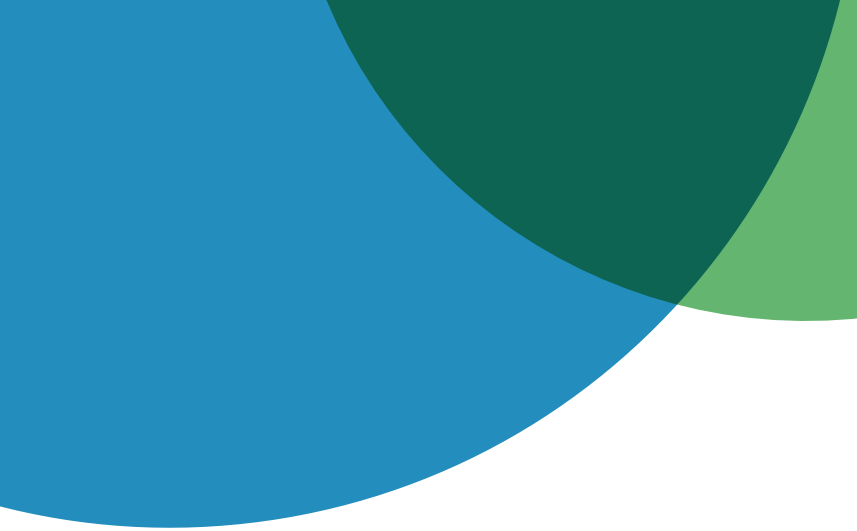

\title{
Childhood behaviour patterns linked with romantic partnering in adulthood
}

\author{
By Dr. Jessica Edwards
}

Children with behavioural disorders, such as ADHD or conduct disorder, are more likely to experience partnership problems in adulthood, including partner conflict and lower relationship satisfaction. ${ }^{1}$ But whether there is an association between commonly observed childhood behaviours and patterns of long-term romantic partnering in adulthood among the general population is unclear. Francis Vergunst and colleagues followed almost 3,000 children across 25 years: they collected teacher-rated behavioural assessments - for inattention, hyperactivity, aggression, opposition, anxiety and prosocial traits - made when children were aged 10 to 12 years, and linked these to their partnering patterns from age 18-35 years based on their relationship status reported in their annual tax returns.

The researchers identified five distinct partnering trajectories: earlypartnered, mid-partnered, late-partnered, early-partnered-separated, and delayed-or-unpartnered. "After adjusting for the child's sex and family background, we found that anxious or inattentive children were more likely to remain unpartnered across early adulthood while those who were aggressive-oppositional were more likely to separate and to spend fewer years partnered", explains Vergunst. "Conversely, prosocial children - those rated by their teachers as being kind, helpful and considerate - showed earlier and more sustained patterns of partnership across early adulthood".

These findings add to growing evidence that children with behavioural problems, even at sub-clinical levels, are more likely to experience social and economic marginalisation as adults, including exclusion from romantic partnership..$^{1-3}$ "Early screening and monitoring are critical as children found to be at-risk could benefit from evidence-based prevention and support programs", speculates Vergunst. "Those with serious difficulties should be considered for specialist educational and clinical input as indicated by formal assessment. This should improve not just partnering prospects but also a wide range of adverse life outcomes that have been repeatedly linked with early behavioural problems".

Referring to:

Vergunst, F. et al. (2020), Behavior in childhood is associated with romantic partnering patterns in adulthood. J. Child Psychol. Psychiatr. doi: 10.1111/ jcpp.13329.

\section{References:}

${ }^{1}$ Buitelaar, N.J.L. et al. (2020). ADHD in childhood and/ or adulthood as a risk factor for domestic violence or intimate partner violence: $A$ systematic review. J. Atten. Disord. 24, 1203-1214. doi: 10.1177/1087054715587099.

${ }^{2}$ Harpin, V.A. (2005). The effect of ADHD on the life of an individual, their family, and community from preschool to adult life. Arch. Dis. Child. 90 Suppl 1, i2-i7. doi: 10.1136/ adc.2004.059006.

${ }^{3}$ Vergunst, F. et al. (2019a). Association between childhood behaviors and adult employment earnings in Canada. JAMA Psychiatry, 76, 1044-1051. doi: 10.1001/ jamapsychiatry.2019.1326. 